\title{
Graefe's Archive for Clinical and Experimental Ophthalmology-introduction of clinical online collection of case reports
}

\author{
David Wong $^{1} \cdot$ Antonia Joussen $^{1} \cdot$ Diana Epstein $^{1}$ (D)
}

Received: 8 August 2016 / Accepted: 17 August 2016 /Published online: 27 August 2016

(C) Springer-Verlag Berlin Heidelberg 2016

Many of us love reading case reports. Whether we are clinicians or scientists, case reports provide the relevance and immediacy to the work we do. They whet our appetite for the curious, the unusual, and the rare. By their nature, rare cases are rare and, as such, may take an individual years of practice to encounter. In essence, clinical case reports can be the distillation of years of clinical experience.

True, some argue that case reports may be of limited scientific merit. Association of one rare condition with another does not imply causation. Indeed, some say that it is dangerous to draw any valid and scientific conclusions from clinical observations in a small number of patients. For this reason, many journals are limiting the publications of case reports. Literally, they do not receive sufficient high priority to justify space within leading journals. This should not, however stop us from reading them.

For this reason, we are putting together a Graefe's Archive Clinical Collection of Case Reports. This will be hosted by the BMC case report journal. With this collaboration, our readers would be able to readily access the well-illustrated case reports in one location via easy links from Graefe's web pages. The JMCR (Journal of Medical

Diana Epstein

graefes_archive@di-ep.com

1 Editorial Office, Di-Ep Biomedical Editorial Services Ltd, "Millworks", 28 Field Road, Glasgow G76-8SE, Scotland, UK
Case reports) Collection will be linked to the GRAE website, and the JMCR Collection page will link to the GRAE website.

We have appointed a panel of editors with wide ranging expertise.

Tina Dietrich, Berlin

Cecilia Fenerty, Manchester

Andreas Stahl, Freiburg

Amira Stylianides, Liverpool

Regular peer review according to JMCR standards, including final acceptance decision by the JMCR Editor-in-Chief or Deputy Editors.

When you access these reports on-line, we feel sure that you will enjoy reading them. No doubt, you will find many gems. Like the apple that fell on Newton's head, we hope some may prove to be the exception that proves the rule and challenge your understanding and inspire you to form new hypotheses.

JMCR has an open peer review policy so the full article pre-publication history will be available online and linked to the published case reports. This includes reviewer reports and all early versions of a manuscript.

$J M C R$ has implemented a streamlined reviewer report based on the CARE Guidelines, which provides a framework for transparent and accurate reporting of case reports. Overall, this creates a simplified and more efficient process of peer review.

The APC (Article Processing Charge) for case reports published in JMCR will be paid for by the author

More importantly, we encourage you to continue to submit your case reports to Graefe's Archives of Clinical and Experimental Ophthalmology. With your permission, we will channel them to this new collection in the Springer family. 